\title{
Personal Characteristics, Workplace Stressors, and Occupational Burnout among Psychiatric Nurses in Southern Taiwan- A Cross-sectional Study
}

\author{
Running head: Occupational Burnout among Psychiatric Nurses
}

\author{
En-Chi Shih ${ }^{1}$, Wen-Li Hou ${ }^{1}$, Pi-Li Lin ${ }^{1}$, Szu-Mei Hsiao ${ }^{1}$, Chien-An Sun ${ }^{2}$, Yu-Ching Chou ${ }^{3}$, TsanYang, \\ ${ }^{1}$ Department of Nursing, Meiho University, Taiwan \\ ${ }^{2}$ Department of Public Health, College of Medicine, Fu Jen Catholic University, Taiwan \\ ${ }^{3}$ School of Public Health, National Defense Medical Center, Taiwan \\ ${ }^{4}$ Department of Health Business Administration, Meiho University, Taiwan
}

Copyright $\bigcirc 2016$ by authors, all rights reserved. Authors agree that this article remains permanently open access under the terms of the Creative Commons Attribution License 4.0 International License

\begin{abstract}
The purpose of this study was to investigate the factors influencing occupational burnout among psychiatric nurses. Psychiatric nurses are often misunderstood and subjected to social bias due to the nature of their work. Their work entails responding to emergencies and they must endure the psychological stress of the threat of aggression from patients. Thus, it is easy for such nurses to experience occupational burnout. A cross-sectional study was undertaken from February to April 2012 among hospitals psychiatric nurses in southern Taiwan. Of 235, 217 nurses eligible for the study completed survey (response rate 92.3\%). Information on personal characteristics, workplace stressors (QMWS), and burnout (MBI) was obtained through structured questionnaire survey. The results indicated that a nurse's age, hospital level, work unit, seniority, psychiatric work, and overtime work were associated with the nurse's level of occupational burnout and its three dimensions. According to our findings, there is positive correlation between job stress and burnout. In addition, our study also showed that overall job stress, total years in nursing, age, maintenance of relationships with patients, personal assessment system, and encountering medical disputes are predictive factors for psychiatric nurses' overall occupational burnout and its three dimensions of emotional exhaustion, depersonalization, and personal accomplishment. In conclusions, our study could help psychiatric nurses to be more aware of their working stress. In order to improve the quality of professional care, hospital management should provide psychiatric nurses with positive and healthy coping strategies.
\end{abstract}

Keywords Psychiatric Nurses, Job Stress, Occupational Burnout

\section{Introduction}

Nursing care is provided in high-stress environments. This not only affects the physical health of nurses in a negative way, it also affects nurses' psychological and mental health, as well as their productivity levels and absence rates. Furthermore, stress may even cause several adverse effects such as increased dissatisfaction, complaints, and an increased death rate among patients $(1,2)$.

According to statistics from May of 2012, there were 231,652 licensed nurses in Taiwan, but the number of active practitioners was only 136,567 , for a practicing rate of $58.95 \%$ (3). Therefore, there is an ongoing staffing shortage of clinical nursing practitioners, with the consequences being a large number of patients who require care, high work pressure, and excessive workloads among practicing nurses. Nurses chronically work excessively long hours and shifts, resulting in fatigue and a high risk of occupational burnout (4-6). In the field of psychiatric nursing, nurse practitioners must continuously manage patients and families from all levels of society, and must deal with multiple communications and complex inter-personal relationships among various medical teams. Both injuries from work and verbal attacks from patients will increase psychiatric nurses' occupational burnout (7-9).

Currently, most studies pertaining to occupational burnout have focused on teachers and school administrators, service personnel, medical professionals, and therapists (10).

For such studies, investigations of medical staff members or nurses in various specialties have mostly focused on investigating job satisfaction, organizational commitment, inclination to resign, and occupational burnout $(11,12)$. If burnout is a common problem in the workplace, it may also influence nurses' motivation and attitudes, work 
performance, and emotional health. This, in turn, has a profound impact on the function and well-being of employees and organizations. Therefore, the goal of this study was to investigate and analyze individual characteristics of psychiatric nurses and key influencing factors of job stress on occupational burnout.

Workplace stressor is a process of the continual interaction between man and workplace. When a person cannot reach balance with his work, workplace stressor appears. The stressors resources of this study include the maintain operation of the medical institution, coping with the hospital accreditation, the stability of the patients' conditions, maintaining the relations with the patients, facing medical disputes, the system of salary payment, the system of individual assessment, promotion or academic research. Personal characteristics included gender, age, education level, marriage status, job training, job title, hospital level, work class, work unit, employment status, total years in nursing, psychiatric tenure, overtime, monthly salary.

It is expected to provide clinical practice to understand the workplace stressors and professional burnout on psychiatric nursing personals; and furthermore, letting administrators understand better the occupational burden of nursing personals, so as to be the foundation and focus of future policy-develop, work deploying, manpower arranging, and training, in order to promote working efficiency and serving quality of nursing personals.

\section{Methods}

\subsection{Study Design}

The study adopted a cross-sectional survey in targeting psychiatric nurses at eleven district-level.

\subsection{Study Setting}

Which provide general outpatient and inpatient healthcare services and have more than 100 acute care beds and acute psychiatric care beds; or above hospitals, such as regional hospitals (over 250 acute care beds) and medical centers (more than 500 acute care beds) in the Kaohsiung-Pingtung area of southern Taiwan.

\subsection{Participants and Data Collection}

To qualify for the study, the nurses had to have been on the job for at least the last three months and they have obtained their registered nurse license at the competent authority of their respective municipality or county/city governments. The questionnaire data collection period was from February to April in 2012. After confirming the hospital of study subjects, first contact the person in charge, explain the research topic and the purpose of the study, get the agreement and then send a letter to the hospital, negotiate the time and way for handing out the questionnaires with the person in charge, take back the written questionnaires two weeks after handing them out. The subjects are full-time nurses that have over three months of clinical working experience.

The questionnaires were self-administered and anonymous, with each participant's consent form and questionnaire sealed in separate envelopes to minimize privacy concerns. Explanations of the study goals and questionnaire content were provided in person for each participating unit before questionnaires were distributed and collected. The study involved the distribution of a total of 235 questionnaires. After screening out incomplete and unidentified questionnaires, the actual number of valid samples in the study was 217 (included 6 males and 211 females, aged between 23-59), for an effective sample recovery rate of $92.3 \%$.

\subsection{Instruments}

According to the related literature and based on consideration of the research variables in this study, the proposed questionnaire was divided into a total of three major parts. The first part consisted of basic information on personal characteristics; the second part consisted of the Questionnaire on Medical Workers' Stress (QMWS); and the third part was the Maslach Burnout Inventory (MBI).

The QMWS scale was designed in accordance with current work content overviews for medical professionals in Taiwan, and possible stressor items unique to the scale were developed in order to completely cover all the stressors affecting medical care professionals. Respondents placed check marks beside items that they themselves believed to be their sources of stress. The overall Cronbach's $\alpha$ value of the original scale was .84 (13).

The MBI scale has been used in studies of job burnout among occupational therapists (trainees), dentists, and psychiatric nurses $(14,15)$. The Cronbach's $\alpha$ value for the psychiatric nurses' original scale total score was .87; the Cronbach's $\alpha$ values for the three dimensions had scores ranging from .76-.88 (14).

The reliability analysis of this study QMWS Cronbach's $\alpha$ value was.81; MBI Cronbach's $\alpha$ value total score was .83; the Cronbach's $\alpha$ values for the three dimensions had scores ranging from .82-.89.

\subsection{Ethical Considerations}

The study was approved by the institutional review board of Meiho University before data collection. Each and every participant was required to sign an informed consent form.

\subsection{Data Analysis}

All statistical analyses were performed using SPSS version 18.0 for Windows. Descriptive statistics included frequency distributions, percentages, means, and standard deviations in order to obtain the distribution of the 
occupational burnout of psychiatric nurses. In addition, independent $t$-tests and one-way ANOVA were used to investigate whether different basic attributes created differences in burnout, and Sheffe's method was implemented on the significantly different variables. Lastly, we used stepwise multiple regressions to gain a further understanding of important predictors influencing burnout in psychiatric nurses. Use stepwise regression to know the important factors of overall burnout, emotional exhaustion, depersonalization, and personal accomplishment of personal characteristics and workplace stressors.

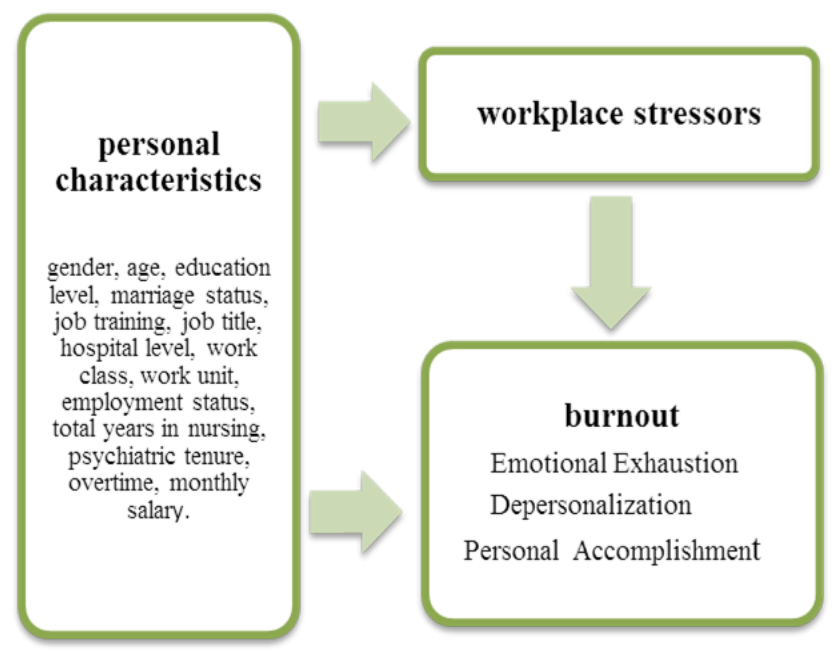

Figure 1. Hypothesized model

\section{Results}

The average score of overall occupational burnout scale was $65.1 \pm 16.2$ points. (Table 1), which falls within the moderate burnout region. As for the average scores for the three dimensions, the emotional exhaustion average score was 27.5 points, the depersonalization average score was 8.3 points, and the personal accomplishment average score was 29.2 points. In the emotional exhaustion dimension, the highest scored item was Item 2.In the depersonalization dimension, the highest scored item was Item 22.In the personal accomplishment dimension, the highest scored item was Item 7.

Among the basic personal characteristics of the psychiatric nurses, age, work unit, total years in nursing, and hours of overtime work were found to statistically significant for "overall occupational burnout" $(\mathrm{p}<.05)$.

The three dimensions was found to be significantly affected by age, work unit, total years in nursing, psychiatric tenure, hospitals level and overtime work $(\mathrm{p}<.05)$. Scheffe post-hoc analyses showed that nurses younger than 30 years of age, nurses with less than 5 years of psychiatric nursing practice experience, working in acute ward and working overtime for more than 2 hours also perceived higher emotional exhaustion and depersonalization (Table 2).

Coefficients for overall job stressors, occupational burnout, and its three dimensions were all statistically significant (data not shown).

The present study used stepwise multiple regression to show personal characteristics and job stressors as predictive factors for occupational burnout. Table 3 showed that with every 1 point increase in overall job stress, there was a 1.279 point increase in overall occupational burnout, there was a 0.550 point increase in emotional exhaustion. In the three dimensions, with every 1 point increase in the scoring for maintaining patient relationships, there was a 2.636 point increase in emotional exhaustion and there was a 1.612 points increase in depersonalization score.

Regression analysis revealed statistical significance $(p<.05)$ for age, total years in nursing, hospital level, personal assessment system, and encountering medical disputes, indicating these are key influencing factors for predicting occupational burnout.

Table 1. Psychiatric nurse burnout scale and distribution of each dimension $(\mathrm{N}=217)$

\begin{tabular}{|c|c|}
\hline Dimension & SD (points) \\
\hline Overall occupational burnout scale score & $65.1 \pm 16.2$ \\
\hline Emotional Exhaustion & $27.5 \pm 10.1$ \\
\hline 1.My job makes me feel emotionally exhausted & $3.5 \pm 1.5$ \\
\hline 2. At the end of the day, I felt completely exhausted & $4.0 \pm 1.5$ \\
\hline $\begin{array}{l}\text { 3.Getting up in the morning, the thought to facing another } \\
\text { day of work makes me feel tired }\end{array}$ & ${ }^{\mathrm{r}} 3.6 \pm 1.6$ \\
\hline $\begin{array}{l}\text { 6. To me, working with other people all day is really a tiring } \\
\text { thing }\end{array}$ & \\
\hline 8.My job makes me feel depleted of energy & $3.5 \pm 1.6$ \\
\hline 13. My job makes me feel frustrated & $2.6 \pm 1.3$ \\
\hline 14. I think I have committed too much at work & $3.3 \pm 1.5$ \\
\hline $\begin{array}{l}\text { 16. Direct contact with others at work brings me too much } \\
\text { stress }\end{array}$ & 2.1 \\
\hline 20. I feel like I have reached the end of myself & $2.5 \pm 1.7$ \\
\hline Depersonalization & $8.3 \pm 6.3$ \\
\hline $\begin{array}{l}\text { 5. I feel that when I face some service clients, they seem to be } \\
\text { objects rather than not people to me. }\end{array}$ & \\
\hline $\begin{array}{l}\text { 10. Ever since I took this job, I have become more ruthless to } \\
\text { others }\end{array}$ & \\
\hline $\begin{array}{l}\text { 11. I worry that this job will make me become emotionally } \\
\text { indifferent }\end{array}$ & \\
\hline $\begin{array}{l}\text { 15. I do not really care about what happen to some of my } \\
\text { clients }\end{array}$ & \\
\hline $\begin{array}{l}\text { 22. I think my clients will blame some of their own problems } \\
\text { on me }\end{array}$ & S 2.2 \\
\hline Personal Accomplishment & $29.2 \pm 8.5$ \\
\hline 4. I can easily understand my clients feeling about things & $3.9 \pm 1.6$ \\
\hline 7. I can be very effective handle problems of my clients & $4.5 \pm 1.4$ \\
\hline $\begin{array}{l}\text { 9. Through my work, I think I bring a positive impact on the } \\
\text { lives of others }\end{array}$ & $3.7 \pm 1$ \\
\hline 12. I think I'm energetic & $3.1 \pm 1.6$ \\
\hline 17. I can easily create a relaxing atmosphere with my clients & $3.9 \pm 1.5$ \\
\hline 18. After working closely with my clients, I feel excited & $3.0 \pm 1.8$ \\
\hline 19. I have completed many valuable things in this job & $3.4 \pm 1.5$ \\
\hline 21. At work, I can calmly deal with emotional problems & $3.8 \pm 1.5$ \\
\hline
\end{tabular}


Table 2a. Difference analysis between basic attributes and overall occupational job burnout score and each dimension $(\mathrm{N}=217)$

\begin{tabular}{|c|c|c|c|c|c|c|c|c|c|c|c|c|c|}
\hline \multirow{2}{*}{ Variables } & \multicolumn{4}{|c|}{ Overall occupational burnout score } & \multicolumn{3}{|c|}{ Emotional Exhaustion } & \multicolumn{3}{|c|}{ Depersonalization } & \multirow{2}{*}{$\begin{array}{c}\text { Personal } \\
\text { Mean } \pm \text { SD }\end{array}$} & \multicolumn{2}{|c|}{ Accomplishment } \\
\hline & $\mathbf{n}$ & Mean \pm SD & $t / F$ & $p$ & Mean \pm SD & $\mathbf{t} / \mathbf{F}$ & $p$ & Mean \pm SD & $t / \mathbf{F}$ & $p$ & & $t / F$ & $p$ \\
\hline Gender & & & .260 & .795 & & .286 & .775 & & .866 & .387 & & -.462 & .644 \\
\hline Male & 6 & $66.8 \pm 15.9$ & & & $28.7 \pm 8.9$ & & & $10.5 \pm 4.8$ & & & $27.7 \pm 7.4$ & & \\
\hline Female & 211 & $65.1 \pm 16.3$ & & & $27.5 \pm 10.2$ & & & $8.2 \pm 6.4$ & & & $29.3 \pm 8.5$ & & \\
\hline Age & & & 3.923 & .021 & & 6.920 & .001 & & 12.727 & $<.001$ & & 3.941 & .021 \\
\hline (1) $\leqq 30$ years old & 81 & \pm 14.7 & & (1) $>$ (3) & $30.2 \pm 9.5$ & & (1) $>$ (3) & $10.3 \pm 6.6$ & & (1) $>$ (3) & $28.1 \pm 8.8$ & & (1) > 1 \\
\hline (2) $31-35$ years old & 65 & $64.9 \pm 16.8$ & & & $27.7 \pm 9.2$ & & & $9.0 \pm 6.3$ & & (2) $>$ (3) & $28.2 \pm 7.4$ & & \\
\hline (3) $\geqq 36$ years old & 71 & $61.3 \pm 16.8$ & & & $24.2 \pm 10.8$ & & & $5.4 \pm 4.9$ & & & $31.5 \pm 8.7$ & & \\
\hline Education level & & & -.625 & .533 & & -.825 & .410 & & -.747 & .456 & & .306 & .760 \\
\hline Vocational education or below & 82 & $64.2 \pm 14.8$ & & & $26.8 \pm 10.1$ & & & $7.9 \pm 6.5$ & & & $29.5 \pm 8.1$ & & \\
\hline College education or above & 135 & $65.7 \pm 17.1$ & & & $27.9 \pm 10.2$ & & & $8.5 \pm 6.2$ & & & $29.1 \pm 8.8$ & & \\
\hline Marriage status & & & .640 & .523 & & .827 & .409 & & 1.937 & .054 & & -1.195 & .233 \\
\hline Without spouse & 111 & $65.8 \pm 15.1$ & & & $28.1 \pm 9.7$ & & & $9.1 \pm 6.4$ & & & $28.6 \pm 8.7$ & & \\
\hline With spouse & 106 & $64.4 \pm 17.4$ & & & $26.9 \pm 10.6$ & & & $7.4 \pm 6.2$ & & & $30.0 \pm 8.2$ & & \\
\hline Job training & & & -.267 & .790 & & .833 & .406 & & .138 & .891 & & -1.560 & .120 \\
\hline Yes & 24 & $64.3 \pm 16.4$ & & & $29.1 \pm 10.3$ & & & $8.5 \pm 5.6$ & & & $26.7 \pm 8.0$ & & \\
\hline No & 193 & $65.2 \pm 16.3$ & & & $27.3 \pm 10.1$ & & & $8.3 \pm 6.4$ & & & $29.6 \pm 8.5$ & & \\
\hline Job title & & & .724 & .470 & & .657 & .512 & & 1.309 & .197 & & -.244 & .808 \\
\hline Clinical staff & 187 & $65.4 \pm 16.3$ & & & $27.7 \pm 10.3$ & & & $8.5 \pm 6.5$ & & & $29.2 \pm 8.4$ & & \\
\hline Team leader or above & 30 & $63.1 \pm 16.0$ & & & $26.4 \pm 8.8$ & & & $7.2 \pm 4.8$ & & & $29.6 \pm 9.2$ & & \\
\hline Employment status & & & 1.083 & .280 & & .560 & .576 & & .497 & .619 & & 1.106 & .270 \\
\hline Full time & 155 & $65.9 \pm 16.0$ & & & $27.7 \pm 9.8$ & & & $8.4 \pm 6.2$ & & & $29.7 \pm 8.0$ & & \\
\hline Temporary & 62 & $63.2 \pm 16.8$ & & & $26.9 \pm 10.9$ & & & $8.0 \pm 6.6$ & & & $28.2 \pm 9.6$ & & \\
\hline Work class & & & -.267 & .790 & & .833 & .406 & & .138 & .891 & & -1.560 & .120 \\
\hline Non-shift & 91 & $64.3 \pm 16.4$ & & & $29.1 \pm 10.3$ & & & $8.5 \pm 5.6$ & & & $26.7 \pm 8.0$ & & \\
\hline Shift & 126 & $65.2 \pm 16.3$ & & & $27.3 \pm 10.1$ & & & $8.3 \pm 6.4$ & & & $29.6 \pm 8.5$ & & \\
\hline
\end{tabular}


Table 2b. Difference analysis between basic attributes and overall occupational job burnout score and each dimension $(\mathrm{N}=217)$

\begin{tabular}{|c|c|c|c|c|c|c|c|c|c|c|c|c|c|}
\hline \multirow{2}{*}{ Variables } & \multicolumn{4}{|c|}{ Overall occupational burnout score } & \multicolumn{3}{|c|}{ Emotional Exhaustion } & \multicolumn{3}{|c|}{ Depersonalization } & \multirow{2}{*}{$\begin{array}{c}\text { Personal } \\
\text { Mean } \pm \text { SD }\end{array}$} & \multicolumn{2}{|c|}{ Accomplishment } \\
\hline & $\mathbf{n}$ & Mean \pm SD & $t / F$ & $p$ & Mean \pm SD & $t / \mathbf{F}$ & $p$ & Mean \pm SD & $t / F$ & $p$ & & $t / \mathbf{F}$ & $p$ \\
\hline Hospital level $^{\#}$ & & & 1.595 & .192 & & 1.930 & .126 & & 5.300 & .002 & & 1.161 & .326 \\
\hline (1)District hospital & 24 & $63.7 \pm 14.8$ & & & $25.9 \pm 8.7$ & & & $6.5 \pm 5.3$ & & (3) $>$ (2) & $31.3 \pm 8.9$ & & \\
\hline (2)Regionalhospital & 76 & $62.2 \pm 16.3$ & & & $25.7 \pm 10.9$ & & & $6.6 \pm 5.4$ & & (4)>(2) & $29.7 \pm 8.6$ & & \\
\hline (3)Specialist hospital & 95 & $67.2 \pm 16.3$ & & & $28.8 \pm 9.7$ & & & $9.4 \pm 7.0$ & & & $29.0 \pm 8.0$ & & \\
\hline (4)Medical center & 22 & $67.9 \pm 16.7$ & & & $29.9 \pm 10.0$ & & & $11.2 \pm 5.7$ & & & $26.8 \pm 9.7$ & & \\
\hline Work unit & & & 6.849 & .001 & & 6.297 & .002 & & 7.919 & $<.001$ & & .688 & .504 \\
\hline (1)Acute ward & 104 & $67.5 \pm 16.2$ & & (1) $>$ (3) & $29.3 \pm 10.0$ & & (1) $>$ (3) & $9.3 \pm 6.2$ & & (1) $>$ (3) & $28.6 \pm 8.5$ & & \\
\hline (2)Chronic ward & 54 & $67.8 \pm 16.1$ & & & $28.1 \pm 10.4$ & & & $9.3 \pm 7.0$ & & (2) $>$ (3) & $30.3 \pm 8.7$ & & \\
\hline (3)Other ward & 59 & $58.6 \pm 14.9$ & & & $23.7 \pm 9.3$ & & & $5.6 \pm 5.1$ & & & $29.4 \pm 8.2$ & & \\
\hline Total years in nursing & & & 3.546 & .031 & & 3.349 & .037 & & 12.323 & $<.001$ & & 2.840 & \\
\hline (1) $\leqq 5$ years & 63 & $67.1 \pm 14.6$ & & n.s & $29.3 \pm 9.5$ & & n.s & $10.6 \pm 6.7$ & & (1) $>$ (3) & $27.1 \pm 9.2$ & & \\
\hline (2)6-10 years & 57 & $68.3 \pm 16.3$ & & & $28.8 \pm 10.1$ & & & $9.5 \pm 6.6$ & & (2) $>$ (3) & $29.9 \pm 7.2$ & & \\
\hline (3) $\geqq 11$ years & 97 & $61.9 \pm 16.8$ & & & $25.5 \pm 10.3$ & & & $6.1 \pm 5.1$ & & & $30.2 \pm 8.5$ & & \\
\hline Psychiatric tenure & & & .686 & .505 & & .958 & .385 & & 6.015 & .003 & & 1.656 & .193 \\
\hline (1) $\leqq 5$ years & 89 & $66.5 \pm 15.2$ & & & $28.6 \pm 9.7$ & & & $9.7 \pm 6.6$ & & (1) $>$ (3) & $28.1 \pm 8.9$ & & \\
\hline (2)6-10 years & 67 & $64.9 \pm 17.5$ & & & $26.7 \pm 10.6$ & & & $8.4 \pm 6.4$ & & & $29.6 \pm 7.5$ & & \\
\hline (3) $\geqq 11$ years & 61 & $63.4 \pm 16.4$ & & & $26.7 \pm 10.2$ & & & $6.1 \pm 5.2$ & & & $30.6 \pm 8.7$ & & \\
\hline Overtime & & & 6.281 & .002 & & 5.573 & .004 & & 1.020 & .362 & & 2.263 & .106 \\
\hline (1) $\leqq 0.5$ hour & 43 & $61.2 \pm 17.2$ & & (3) $>$ (1) & $24.5 \pm 9.7$ & & (3) $>$ (1) & $7.5 \pm 6.3$ & & & $29.3 \pm 8.6$ & & \\
\hline (2) $1-1.5$ hour & 110 & $63.3 \pm 15.1$ & & (3)>(2) & $26.8 \pm 9.7$ & & (3) $>$ (2) & $8.1 \pm 6.1$ & & & $28.2 \pm 8.5$ & & \\
\hline (3) $\geqq 2$ hour & 64 & $70.9 \pm 16.3$ & & & $30.7 \pm 10.4$ & & & $9.2 \pm 6.7$ & & & $31.0 \pm 8.3$ & & \\
\hline Monthly salary & & & .014 & .987 & & .158 & .854 & & .730 & .483 & & 1.422 & .243 \\
\hline (1) $\leqq 30,000$ yuan & 48 & $65.4 \pm 15.5$ & & & $28.0 \pm 10.2$ & & & $8.6 \pm 6.7$ & & & $28.6 \pm 9.3$ & & \\
\hline (2) $3-50,000$ yuan & 154 & $65.0 \pm 16.5$ & & & $27.5 \pm 10.2$ & & & $8.4 \pm 6.3$ & & & $29.1 \pm 8.0$ & & \\
\hline (3) $\geqq 50,000$ yuan & 15 & $65.5 \pm 17.6$ & & & $26.3 \pm 9.9$ & & & $6.4 \pm 5.2$ & & & $32.7 \pm 10.4$ & & \\
\hline
\end{tabular}

Using t-test, ANOVA and Scheffe post-hoc analyses. Significant difference $\alpha=.05$

Note:\#

1. District hospitals which provide general outpatient and inpatient healthcare services and have more than 100 acute care beds and acute psychiatric care beds

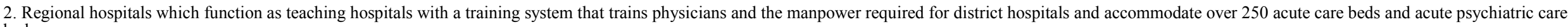

3. Specialty hospitals that are devoted to a single specialty, such as psychiatric hospitals.

4. Medical centers which provide research, educational training, and advanced medical practice and have more than 500 acute care beds and psychiatric care beds. 
Table 3. Stepwise multiple regression analysis of factors influencing psychiatric nurse basic characteristics and job stressors on occupational burnout $(\mathrm{N}=$ 217)

\begin{tabular}{|c|c|c|c|c|}
\hline Variables & $\beta$ & $\mathrm{R}^{2}$ & $\mathrm{~T}$ & $\mathrm{~F}$ \\
\hline \multicolumn{5}{|c|}{ Overall Occupational burnout } \\
\hline Constant & 15.839 & & $2.297 *$ & \\
\hline Overall job stressor & 1.279 & .175 & $6.798 * * *$ & $45.574 * * *$ \\
\hline Total years in nursing (6-10 years vs 11 years or above) & 5.369 & .194 & $2.395^{*}$ & $25.797 * * *$ \\
\hline Age( 30 years old or younger vs 36 years old or older) & 4.755 & .214 & $2.327 *$ & $19.358 * * *$ \\
\hline \multicolumn{5}{|c|}{ Emotional Exhaustion } \\
\hline Constant & -5.395 & & -1.296 & \\
\hline Overall job stressor & .550 & .212 & $3.764 * * *$ & $57.804 * * *$ \\
\hline Maintaining patient relationship & 2.636 & .255 & $3.337 * * *$ & $36.651 * * *$ \\
\hline Age( 30 years old or younger vs 36 years old or older) & 4.960 & .279 & $3.543 * * *$ & $27.439 * * *$ \\
\hline Age(31-35 years old vs 36 years old or older) & 3.612 & .299 & $2.454 *$ & $22.571 * * *$ \\
\hline \multicolumn{5}{|c|}{ Depersonalization } \\
\hline Constant & -4.333 & & $-2.109^{*}$ & \\
\hline Maintaining patient relationship & 1.612 & .113 & $3.936 * * *$ & $27.303^{* * *}$ \\
\hline Total years in nursing ( 5 years or below vs. 11 years or above) & 3.596 & .159 & $3.942 * * *$ & $20.253^{* * *}$ \\
\hline Total years in nursing $(6-10$ years vs. 11 years or above $)$ & 3.112 & .198 & $3.323 * * *$ & $17.537 * * *$ \\
\hline Personal assessment system & 1.188 & .237 & $2.933 * *$ & $16.427 * * *$ \\
\hline Hospital level (Regional hospital vs. Medical center) & -1.609 & .251 & $-1.992 *$ & $14.119 * * *$ \\
\hline \multicolumn{5}{|c|}{ Personal Accomplishment } \\
\hline Constant & 20.394 & & $6.155^{* * *}$ & \\
\hline Total years in nursing ( 5 years or below vs 11 years or above) & 4.098 & .024 & $3.106 * *$ & $5.329 *$ \\
\hline Age( $31-35$ years old vs 36 years old or older) & 2.691 & .048 & $2.042 *$ & $5.431 * *$ \\
\hline Encountering medical disputes & -1.712 & .067 & $-2.732 * *$ & $5.073^{* *}$ \\
\hline Maintaining patient relationship & 1.321 & .086 & $2.132 *$ & $5.004 * * *$ \\
\hline \multicolumn{5}{|l|}{$* \mathrm{p}<.05, * * \mathrm{p}<.01, * * * \mathrm{p}<.001$ 。 } \\
\hline \multicolumn{5}{|l|}{ Note: } \\
\hline \multicolumn{5}{|l|}{ 1. The current regression model is based on stepwise multiple regression. } \\
\hline \multicolumn{5}{|c|}{$\begin{array}{l}\text { 2. Variables included in the analysis include: basic attributes (age, gender, education level, job title, employment status, monthly salary, total years in } \\
\text { nursing, tenure in psychiatry, overtime, hospital level, and work units), overall job stressor score, and eight items. }\end{array}$} \\
\hline \multicolumn{5}{|c|}{$\begin{array}{l}\text { 3. Total years in nursing are grouped as } 1: 5 \text { years or less and 2: 6-10 years, with reference group of } 11 \text { years or above. } \\
\text { 4. Age is grouped as } 1: 30 \text { years old or younger and } 2: 31-35 \text { years old, with reference group of } 36 \text { years old or older }\end{array}$} \\
\hline \multicolumn{5}{|c|}{ 4. Age is grouped as 1: 30 years old or younger and 2: $31-35$ years old, with reference group of 36 years old or older } \\
\hline
\end{tabular}

\section{Discussion}

Occupational stress and burnout in nurses pose a threat to patient safety, and the effects they cause should not be ignored. Not only do they reduce the quality of healthcare but they also endanger the safety of patients $(16,17)$.

Occupational stress is the main cause of occupational burnout. It not only damages individual's health, but also influences individual's working performance and attitude. When an individual faces working load but lacks of working control and social support, it would lead to occupational burnout $(18,19)$.

The nurses' occupational burnout would lead to emotional burnout, lack of humanity and reduced personal accomplishment, which are the results of occupational stress. There's a close relationship between occupational stress and occupational burnout (20). As the result of this study has shown, the overall job stressor and overall occupational burnout sensitivities are higher, which is the highest sensitivity toward emotional burnout among the three dimensions; this result is similar to the previous study $(21,22)$. Emotional burnout affects the feelings toward working load; when individual's level of emotional burnout increases, the stressed feeling toward working load also increases (23).

In this study, results from the analysis of the differences in occupational burnout based on the basic personal characteristics of psychiatric nurses show that for "overall occupational burnout," younger nurses have more severe occupational burnout. This result is similar to previous studies $(14,15,24)$. Nurses working at acute wards, or working overtime more than 2 hours a day have significantly higher overall occupational burnout. This increased burnout may be due to the unstable conditions and complexities of 
patients in the acute wards who require more effort to deal with. This result is similar to that of a previous study $(25,26)$. In this study, we also found that nurses with 6-10 years' experience have higher overall occupational burnout than nurses with less than 5 years or more than 11 years' experience. This result is similar to the finding from $\mathrm{Su}$ (27) that middle generation nurse practitioners (those with 6-10 years' experience) are given heavy responsibilities at work, and also the multiple roles during this stage may explain why mid-generation nurses experience burnout more often.

For the "emotional exhaustion" dimension, nurses who are younger, with shorter working duration, working at acute units, and who work overtime more than 2 hours a day have greater emotional exhaustion. These results are similar to those of previous studies $(15,26,28,29$,). This may be due to the insufficient clinical experience of younger nurses with shorter working duration causing them to become exhausted more easily at work, leading to their perception of burnout and fagitue. Chronic work stress can deplete one physically and mentally, which is eventually reflects in one's long-term inter-personal stress at work. Furthermore, the interactive relationships between medical personnel and patients result in a high risk of emotional exhaustion $(30,31)$. Studies show that stressors in work environments are closely related to occupational burnout. They are especially related to the feeling of emotional exhaustion (32-35).

For the "depersonalization" dimension, nurses who are younger, with shorter working duration, and working at specialty or acute hospitals have greater perceptions of depersonalization. This may be due to the fact that different levels of stress are experienced during nurse practice at different medical facility levels with different characteristics. Conditions of patients in acute wards change quickly with great fluctuations, so nurses working at acute units need to keep highly alert to observe conditions and manage patients' conditions. Therefore, nurses at acute units have higher perceptions in the depersonalization dimension than nurses at other units. Persistent work pressure causes nurses to doubt their own ability and have a weakened sense of self-worth, leading to the occurrence of depersonalization (36). As for the factor of hospital level, there is a difference in dehumanization between nurses working at regional hospitals and those working at medical centers, with a higher score for nurses working at medical centers. It is worth further investigating if care resources, manpower structures, the natures of work, or work cultures are different at the different levels of hospitals that nurses work at.

For the "personal accomplishment" dimension, nurses over 36 years old had higher personal accomplishment than younger nurses. This may be due to younger nurses' lack of experience in work or stress adjustment. Therefore, when younger nurses have different opinions or conflicts with patients, family members, and co-workers, they are more likely to perceive that they are not being supported or cared about. Results from our study show that higher scores in personal accomplishment are observed in nurses with experience of less than 5 years of experience as compared to those with over 11 years of experience, and higher in nurses 31-35 years old as compared to those over 36 years old. This may be due to younger and less experienced nurses being able to get motivated by the freshness of experiences at work. Although emotional or physical exhaustion can be produced during nurses' handling of complex problems or emotions from patients and their family members, nurses can also get rewards and find a source of achievement if they can effectively improve and control the problems of the patients and their family members to meet work requirements (37). Therefore, for the maintenance patients relationships, a better therapeutic inter-personal relationship is associated with higher personal accomplishment. Conversely, when nurses encounter medical disputes, being unable to effectively handle problems and no longer feeling excited about their work diminished personal accomplishments (38). In addition, the reasons for nurses' occupational burnout may vary according to the different backgrounds of medical institutions, organizational cultures and leadership styles, nurses' levels of professional competence, or labor inequalities due to work allocation problems that cause different stressors and occupational burnout.

The results of our study can provide references for psychiatric nurses to assist them in understanding their perceptions of stress, as well as provide them with positive and healthy coping strategies to prevent occupational burnout and promote quality in professional psychiatric nursing care.

\subsection{Practical Implications}

Mental health care emphasizes a patient-centered model of caring, nursing personals must apply professional skills and practical experience to make the appropriate medical treatment on cases of physical and mental health problems. Nursing personals not only have to take care of the patients' daily lives, coordination and execution of various drugs treatment, but also need to focus on the patient's inner feelings, thinking, behaving and interpersonal relationships. Nursing personals must develop objective emotion to grasp more clearly the problems and needs of patients, and solve them organized. In short, the psychiatric nursing job is challenging, nursing personals should establish a correct concept of career and values, learn to use knowledge of psychology to self-adjust, treat a variety of psychological distress positively, and take the appropriate method to make adjustments. And managers have to improve the working environment, to establish nursing support systems, to reduce and eliminate the work pressure, improve service quality, and promote the development of the nursing profession.

\section{Limitations}

There are several noteworthy limitations of our study. Because the participants were limited to 217 psychiatric nurses at eleven hospitals of different levels in the 
Kaohsiung-Pingtung area in southern Taiwan, selection bias could not be avoided. Therefore, the study's findings cannot be generalized to all psychiatric nurses. Furthermore, the enrolled participants were limited to currently employed clinical nurses, therefore it is possible that the subgroup of nurses who actually felt the highest level of stress or burnout may have already resigned from work or transferred to other selective administrative work. Our study also did not collect sufficient information on marriage and family stress, peer relationships, or the support levels from colleagues and supervisors. It is possible that residual confounding by these factors may also affect the predictive factors and occupational burnout link. In addition, the study used a cross-sectional study design, which entails limits on the inferences of cause-effect relationships.

\section{Conclusions}

Predictive factors for psychiatric nurses' overall occupational burnout and its three dimensions, emotional exhaustion, depersonalization, and personal achievement, are overall job stress, total duration of nursing practice, age, maintenance of relationships with patients, personal assessment system, and encounters with medical disputes.

Based on the research findings, the occupational stress and burnout in psychiatric nurses can be categorized as moderate stress. It is suggested that they regularly attend courses to help alleviate stress to learn stress management, self-control, time management, relaxation techniques, and form peer support groups and social support systems to expand support networks as these have been confirmed effective in reducing burnout $(39,40)$.

Future research can focus on the moderate to severe burnout participants in this study and design an effective method to initiate these measures. Intervention studies can investigate improvements in occupational stress and burnout and employ the newly created intervention method to increase nurses' sense of achievement and satisfaction in their work, thereby enhancing the quality of healthcare.

In addition, the sense of accomplishment in workplace can also be used in future study, the sense of accomplishment is both the higher level of psychological need in work and the motivation of staying in a profession in a long-term stability. Even more, it also stimulates creativity, making the psychiatric nurses love their jobs more, and higher their level of self-worthiness and service quality.

\section{REFERENCES}

[1] Van Dick, R., \& Wagner, U. (2001). Stress and strain in teaching: a structural equation approach. British Journal of Educational Psychology, 71(2), 243-259.

[2] Vahey, D.C., Aiken, L.H., Sloane, D.M., Clarke, S.C., \& Vargas, D. (2004). Nurse burnout and patient satisfaction.
Medical Care, 42, II57- II66.

[3] The National Union of Nurses Association ROC. (2012). [cited 2012 June 16] Available from: http://www.nurse.org.t w/defaultNewsView.aspx?newsID $=1571 \&$ timeStamp $=1323$ 476498890 .

[4] Mann, S., \& Cowburn, J. (2005). Emotional labour and stress within mental health nursing. Journal of Psychiatric and Mental Health Nursing, 12 (2), 154-162.

[5] McMlure, R., \& Murphym, C. (2007). Contesting the dominance of emotional labour in professional Nursing. Journal of Health Organization and Management, 21(2), 101-120.

[6] Mariann, K., Eszter, K., \& Katalin, H. (2010). Emotion work and burnout: cross-sectional study of nurses and physicians in Hungary. Croatian Medical Journal, 51(5), 432-442.

[7] Liu, J., \&Wuerker, A. (2005). Biosocial bases of aggressive and violent behavior-implications for nursing studies. International Journal of Nursing Studies, 42(2), 229-241.

[8] Flannery, R.B., Farley, E., Rego, S., \& Walker, A.P. (2007). Characteristics of staff victims of psychiatric patient assaults: 15-year analysis of the Assaulted Staff Action Program (ASAP).Psychiatric Quarterly, 78(1), 25-37.

[9] Hanrahan, N.P., Aiken, L.H., McClaine, L., \& Hanlon, A.L. (2010). Relationship between Psychiatric Nurse Work Environments and Nurse Burnout in Acute Care General Hospitals. Issues in Mental Health Nursing, 31(3), 198-207.

[10] Hung, J.P. (2013). Studies on Burnout in Taiwan: A Critical Review. Journal of Advanced Human Resource Management, 13(3), 107-140.

[11] Chiou, M.J., See, L.C., Huang, Y.H., Chang, H.J., \& Lin, S.R. (2013). Burnout and Quit Intention among Clinical Nurses in Taoyuan during Global Budget Payment System. St. Joseph' Hospital Medical \& Nursing Journal, 7(1), 33-44.

[12] Chu, C.I. (2013). The Impact of hospital nurses emotional labor on job satisfaction and burnout. Taiwan Journal of Public Health, 32(3), 266-278.

[13] See, L.C., Chang, H.J., Liu, M.J., \& Cheng, H.K. (2007). Development and evaluation of validity and reliability of a questionnaire on medical workers' stress. Taiwan Journal of Public Health, 26(6):452-461.

[14] Hsieh, C.J., Hsieh, H.Y., Chen, P.H., Hsiao, Y.L., \& Lee, S. (2004). The relationship between hardiness, coping strategies and burnout in psychiatric nurses. The Journal of Nursing, 51(3), 24-33.

[15] Lu, L., Lee, H.M., \& Shieh, T.Y. (2005). Occupation stress, health and occupational burnout among dentists: a study of clinical dentists in Kaohsiung. Research in Applied Psychology, 27, 59-80.

[16] Steele, M.T., Ma, O.J., Watson, W.A., Thomas, H.A., \& Muelleman, R.T. (1999). The occupational risk of motor vehicle collisions for emergency medicine residents. Academic Emergency Medicine, 6(10), 1050-1053.

[17] Teng, C.I., Shyu, Y.I., Chiou, W.K., Fan, H.C., \& Lam, S.M. (2010). Interactive effects of nurse-experienced time pressure and burnout on patient safety: a cross-sectional survey. International Journal of Nursing Studies, 47(1), 1442-1450. 
[18] Kickul, J., \&Posig, M. (2001). Supervisory emotional support and burnout: an explanation of reverse buffering effects. Journal Managerial Issues, (3), 328-344.

[19] Schaufeli, W.B., \& Bakker, A.B. (2004). Job demands, job resources, and their relationship with burnout and engagement: a multi-sample study. Journal Organizational Bebavior, 25(3), 293-315.

[20] Braithwaite, M. (2008). Nurse Burnout and Stress in the NICU. Advances In Neonatal Care, 8(6), 343-347.

[21] Li, W.C., \& Chang, S.H. (2009). A Study of Employees Attending Leisure Sports on Job Stress and Burnout. Journal of Leisure and Tourism Industry Research, 4(2), 71-83.

[22] Piko, B.F. (2006). Burnout, role conflict, job satisfaction and psychosocial health among Hungarian health care staff: a questionnaire survey. International Journal of Nursing Studies, 4(3), 311-318.

[23] Huang, Y.H., Huang, I.C., Chen, C.H., \& Du, P.L. (2015). The reciprocal effects of psychosocial job characteristics, burnout and health among nurses: a panel study. Taiwan Journal Public Health, 34(2), 204-217.

[24] Chuang, H.H., \& Yang, S.F. (2011). An analysis of the relationship between job burnout and organization commitment among staff nurses: a case study in a regional teaching hospital in central Taiwan. Cheng Ching Medical Journal, 7(2), 51-60.

[25] Ilhan, M.N., Durukan, E., Tangerm E., Maral, I., \&Bumin, M.A. (2008). Burnout \& its correlated among nursing staff: questionnaire surve. Journal of Advanced Nursing, 61(1), 100-106.

[26] Wu, X.L., Cai, W.X., \& Hsu, C.H. (2010). The Study of Occupational Burnout of Nursing Staff to Leisure Coping Strategies. Leisure Industry Research, 8(3), 145-167.

[27] Su, M.H. (2008). Emotion Regluation in the Workplace of Nurses (Unpublished master's thesis).National Taipei University of Technology Institute of Commerce Automation and Management.

[28] Hwang, W.T., Chu, T.F., Lu, S.J., \& Hsu, C.C. (1996). A study of Burn-Out in Occupational Therapists. Journal of Occupational Therapy Association, 14, 35-53.

[29] Chen, Y.C., \& Lin, L.H. (2002). Relationships between empowerment and organizational commitment of nurses. Tzu Chi Nursing Journal, 1(4):53-64.
[30] Maslach, C., Leiter, M.P., \&Schaufeli, W.B. (2008). Measuring burnout. In: Coopper CL., Cartwright S., editors. The Oxford handbook of organizational well-being. Oxford (UK): Oxford University Press, 86-108.

[31] Garrosa, E., Moreno, J.B., Liang, Y., \& Gonzalez, J.L. (2008). The relationship between socio-demographic variables, job stressors, burnout, and hardy personality in nurses: an exploratory study. International Journal of Nursing Studies, 45(3), 418-427.

[32] Lee, R.T., \& Ashforth, B.E. (1996). A meta analytic examination of the correlates of the three dimensions of job burnout. Journal of Applied Psychology, 81,123-133.

[33] Maslach, C., Schaufeli, W.B., \& Leiter, M.P. (2001). Job burnout. Annual Review of Psychology, 52, 397-422.

[34] Jawahar, I.M., Stone, T.H., \& Kisamore, J.L. (2007). Role conflict and burnout: the direct and moderating effects of political skill and perceived organizational support on burnout dimensions. International Journal Stress Management, 14(2), 142-159.

[35] Santavirta, N., Solovieva, S., \& Theorell, T. (2007). The association between job strain and emotional exhaustion in a cohort of 1,028 Finnish teachers. British Journal of Educational Psychology, 77(1), 213-228.

[36] Jasna, H.K., Barbara, K.M., \& Nada, K. (2011). Personality, organizational stress, and attitudes toward work as prospective predictors of professional burnout in hospital nurses. BMJ Croatian Medical Journal, 52(4), 538-549.

[37] Brotheridge, C.M., \& Grandey, A.A. (2002). Emotional labor and burnout: Comparing two perspectives of" people work". Journal of Vocational Behavior, 60(1), 17-39.

[38] Ivancevich, J.M., Konopaske, R., \& Matteson, M. (2005). Organizational behavior and management (7th ed.). New York: McGraw-Hill.

[39] Schaufeli, W.B., \& Buunk, B.P. (2003). Burnout: An overview of 25 years of research and theorizing. In M. J. Schabracq, J. A. M. Winnubst, \& C.L. Cooper, (Eds.).The handbook of work and health psychology (2nd ed.).John Wiley \& Sons, New York, 383-425.

[40] Shirom, A. (2003). Job-related burnout: A review. In J. C. Quick \& L. E. Tetrick (Eds.).Handbook of occupational health psychology. DC: American Psychological Association, Washington,3-18 